\title{
Bir Bizans Teknesinin Anatomisi: Yenikapı 8 Batığı*
}

\section{Işı Özsait Kocabaş}

Öz

Yenikapı 8 battğı (YK8), İstanbul, Yenikapı'da, İstanbul Arkeoloji Müzeleri tarafindan gerçekleştirilen kurtarma kazıları sırasında 2006 yılında keşfedilmiştir. Theodosius Limanı́nın sediment dolgusu içinde, kazı alanının güney tarafinda bulunan battk, tabakasına göre MS 10. yüzyıla tarihlendirilmiştir. Batğın korunan uzunluğu $5 \mathrm{~m}$ ve genişliği 2,9 m’dir. Omurgası, 19 adet kaplama tahtası, 13 adet döşeği bulunan batı̆ı̆ın yaklaşık yarısı palplanş duvarı altında kalmıştır. YK8, kazı alanında, geleneksel üç nokta ölçüm ve çizimleri, birebir ölçekli asetat çizimleri, fotoğraf ve foto-mozaik çekimleriyle in situ olarak belgelenmiştir. Sonrasında battk ahşapları sökülerek, iÜ Yenikapı Batkkları Araştırma Merkezi'ndeki havuzlara taşınmıştır. Yenikapı'nın kenar-kavelalı ve düz dipli tekneler grubu içinde yer alan YK8, Akdeniz karma yapım yöntemi ile inşa edilmiştir. Ön rekonstrüksiyon çalışmalarına göre, teknenin orijinal boyutlarının $12 \mathrm{~m}$ uzunlukta ve $4 \mathrm{~m}$ genişlikte olduğu hesaplanmıştı. Bu makalede, YK8 battğııın kazısı ve belgelenmesinde uygulanan metodoloji ve batığın genel konstrüksiyon özellikleri diğer Yenikapı batkkları ile karşılaştırmalı olarak değerlendirilmiştir.

\section{Anahtar Kelimeler}

Yenikapı batkkları • Karma inşa yöntemi • Belgeleme

\section{The Anatomy of a Byzantine Vessel: Yenikapı 8 Shipwreck}

\begin{abstract}
The shipwreck Yenikapı 8 (YK8) was discovered in Yenikapı, Istanbul, in 2006 during the rescue excavations carried out by Istanbul Archaeological Museums. The shipwreck, which was found within the sediment-filled Theodosian Harbour in the southern side of the excavation area, was dated to the 10th century AD according to the stratigraphic layer. Its remains measure only $5 \mathrm{~m}$ long and $2.9 \mathrm{~m}$ wide. The shipwreck comprises the keel, nineteen strakes of planking and thirteen floor-timbers. In fact, approximately half of the vessel lies under the sheet pile wall. YK 8 was documented in situ with traditional triangulation measurements and drawings, full-scale clear acetate drawings, photography and photomosaics. Then the hull members were dismantled and moved to the storage tanks at the IU Yenikapı Shipwrecks Research Centre. YK 8 which was studied amongst the flat-floored shipwrecks with planking edge dowels of the Yenikapı Site, was built using a Mediterranean mixed construction technique. The original dimensions of the vessel were estimated at about $12 \mathrm{~m}$ in length and $4 \mathrm{~m}$ in breadth according to preliminary reconstruction studies. In this article, the excavation, documentation methodology and basic construction features of YK 8 were discussed, along with its structural similarities to other Yenikapı shipwrecks.
\end{abstract}

\section{Keywords}

Yenikapı shipwrecks • Mixed construction technique • Documentation

* iÜ Yenikapı Batıkları Projesi, İstanbul Üniversitesi Bilimsel Araştırma Projeleri Birimi (Proje no: 2294, 3907, 7381, 12765) tarafindan desteklenmiştir.

** Sorumlu Yazar: Işıl Özsait Kocabaş (Dr. Öğr. Üyesi), İstanbul Üniversitesi, Edebiyat Fakültesi, Taşınabilir Kültür Varlıkları ve Onarımı Bölümü, Sualt Kültür Kalıntılarını Koruma Anabilim Dalı, İstanbul, Türkiye. Eposta: isilozsait@gmail.com Atıf: ÖZSAiT KOCABAŞ, Işıl, “Bir Bizans Teknesinin Anatomisi: Yenikapı 8 Batığı”, Art-Sanat, 11(Ocak 2019), s. 325-338. https://doi.org/10.26650/artsanat.2019.11.0015 
"Tarihi Yarımada" sınırları içinde yer alan Yenikapı semtinde 2004-2013 yıllar1 arasında İstanbul Arkeoloji Müzeleri tarafından sürdürülen kurtarma kazıları, Konstantinopolis'in Marmara Denizi'ne bakan büyük limanlarından biri olan Theodosius Limanı'nı gün ışığına çıkarmıştır. ${ }^{1}$ Gerçekleştirilen kazılarda, İstanbul'un kültür tarihini zenginleştiren pek çok arkeolojik buluntu ve yaklaşık 600 yıllık süre içinde farklı zamanlarda batmış 37 adet gemi kalıntısı, siltlenme ile oluşan dolgu katmanları içinde keşfedilmiştir. ${ }^{2}$ Bu muazzam koleksiyonun bir parçası olan Yenikapı 8 batı̆̆1 (YK8), müze arkeologları tarafından 2016 yılında Yenikapı kazı alanının güney sınırında, yeri değiştirilen bir atık su kanalının inşası sırasında bulunmuştur (G. 1). Batık, tabakasına göre MS 10. yüzyıla tarihlendirilmiştir. YK8'in ahşapları üzerinde gerçekleştirilen bilimsel çalışmalar halen devam etmektedir.

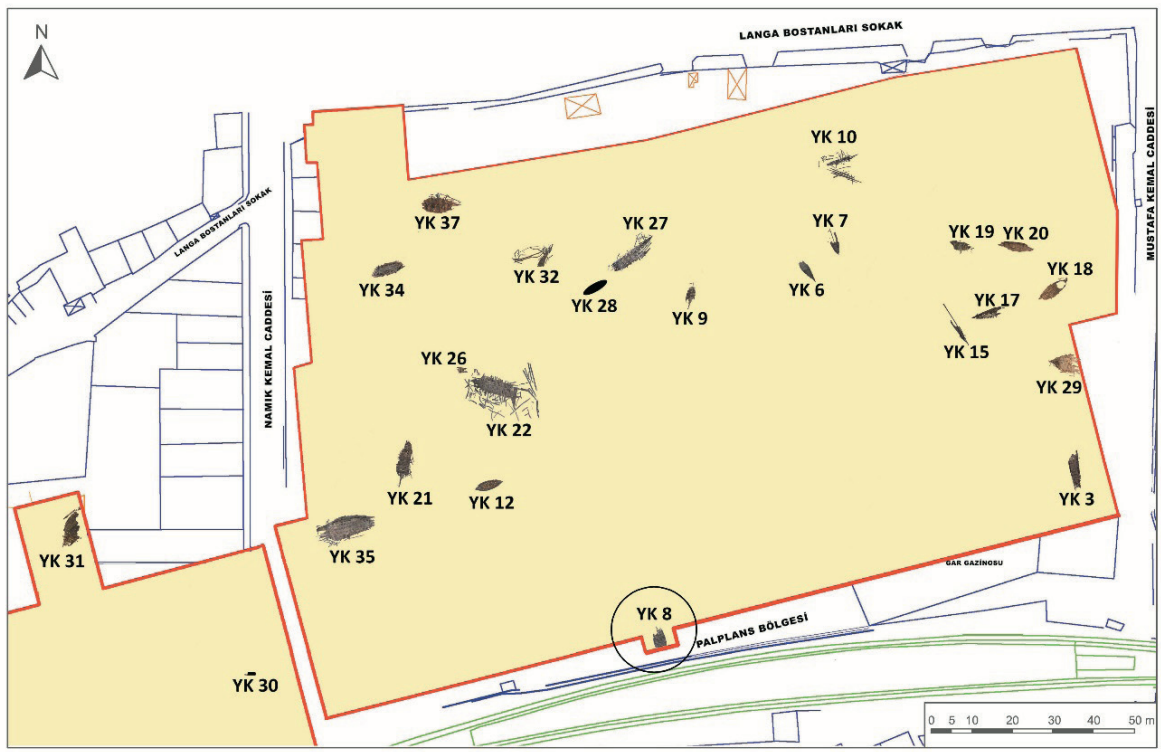

G. 1: Yenikapı kazı alanında YK8 batığının konumu (ï̈̈ Yenikapı Batıkları Projesi Arşivi)

\section{Batığın Kazısı}

Yenikap1 8, İstanbul Üniversitesi Yenikapı Batıkları Projesi ekibinin belgeleyerek alandan kaldırdığı dördüncü batıktır. Kazı alanında YK 8 batığı üzerindeki çalışmalar Aralık 2016 ve Şubat 2007 tarihleri arasında sürdürülmüştür. S21-22 plan karelerinde, $-0,90$ ve 1,26 kotları arasında konumlanmış olan YK8, alan kazılmadan önce, demiryolu hattının çökmemesi için zorunlu olarak inşa edilen çelik duvarın (palplanş)

1 Zeynep Kızıltan, "Excavations at Yenikap1, Sirkeci and Üsküdar with in Marmaray and Metro Projects, Istanbul Archaeological Museums", Proceedings of the $1^{\text {st }}$ Symposium on Marmaray-Metro Salvage Excavations $5^{\text {th }} \mathbf{6}^{\text {th }}$ May 2008, Ed. Ufuk Kocabaş, Istanbul 2010, s. 1-16.

2 Yenikapı batıkları, İstanbul Arkeoloji Müzeleri, İstanbul Üniversitesi ve Texas A\&M Üniversitesi tarafından çalışılmaktadır. 
altında kalmış durumda ele geçmiştir. Yarıya yakın kısmı bu duvar tarafından kesilerek kazı alanının dışında bırakılmış olan YK8'in çevresi çimento atıkları, moloz döküntüleriyle kaplıdır. Buna ilaveten kanalın içi su ile doludur. Batığın bulunduğu konum nedeniyle üzerine koruyucu çadır yapılamamış, bunun yerine iki tarafındaki palplanşlara bağlanan örtme ve atomize sulama sistemi kurulmuştur.

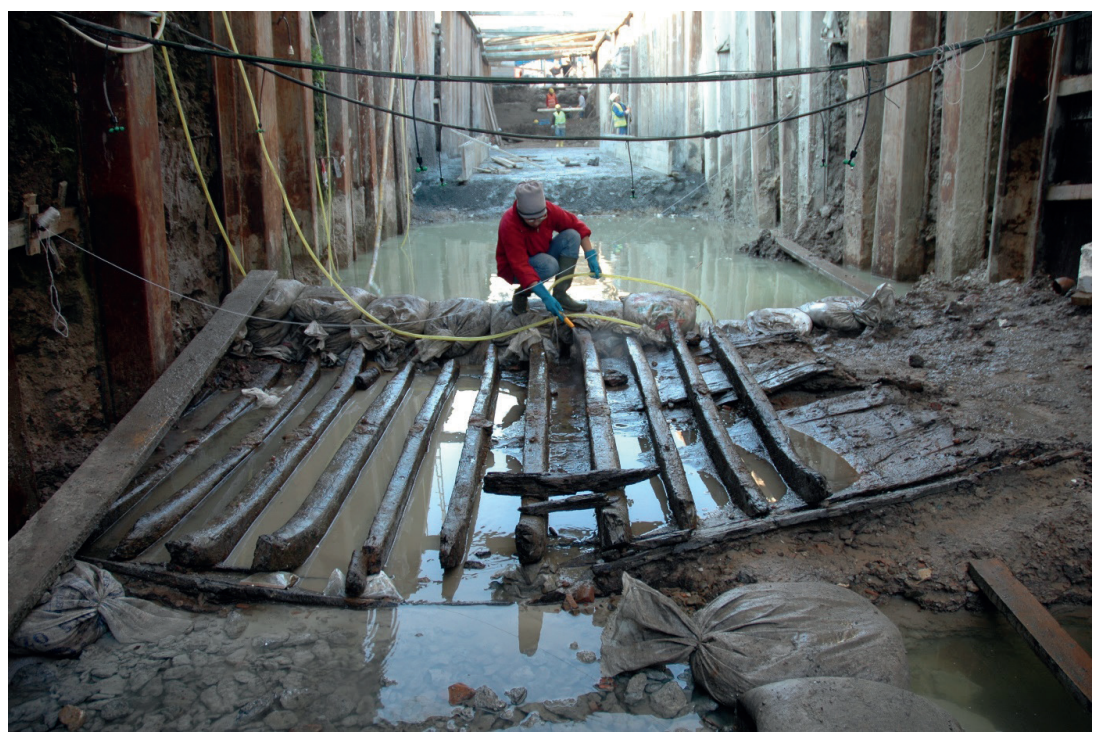

G. 2: Batığın ilk durumu ve temizlik çalışması (İÜ Yenikapı Batıkları Projesi Arşivi)

Batığın çevresindeki su boşaltıldıktan ve üzerindeki çamur tabakası temizlendikten sonra belgeleme çalışmaları başlamıştır (G. 2). Batık gövdesinin ölçümlerinde geleneksel üçgenleme yöntemi kullanılmıştır (G. 3). Bu yolla batık üzerinde belirlenen binlerce noktanın her birinin, 3 ayrı röper noktasından çekilen şerit metrelerle ölçümleri alınmış ve bunların kağıt üzerinde birleştirilmesiyle oluşan çizimleri yapılmıştır. Sonrasında bu paftalar taranarak bilgisayar ortamında çizilmiştir. Ölçekli plan ve kesit çizimlerinin yanı sıra, batığın iç ve dış kaplama tahtaları gerçek boyutlarında asetata kopyalanmıştır. Kaplamaların üzerine serilen asetat tabakalara, sabit kalemlerle kaplama hatları, ahşap damarları, birleşim yerleri, boş çivi delikleri, demir ve ahşap çiviler, alet izleri, serme kalafat ve macunlar ile yapım yöntemine dair pek çok veri, değişik renk ve tarama şekilleriyle işlenmiştir. Fotoğraf çekimlerinin yanı sıra batığın eğrili ve dış kaplamalı iki foto-mozaiği yapılmıştır. Belgeleme çalışmaları, batığın genel durumu ve elemanların sökülmesi sırasında ortaya çıkan detayların işlendiği el çizimleri ve görsel notlarla desteklenmiştir. ${ }^{3}$

3 Işıl Özsait Kocabaş, “III. Documentation: Reading the Timber”, The 'Old Ships' of the 'New Gate' 1, Yenikapı Shipwrecks, Vol. I, Ed. Ufuk Kocabaş, Istanbul 2008, s. 27-72. 


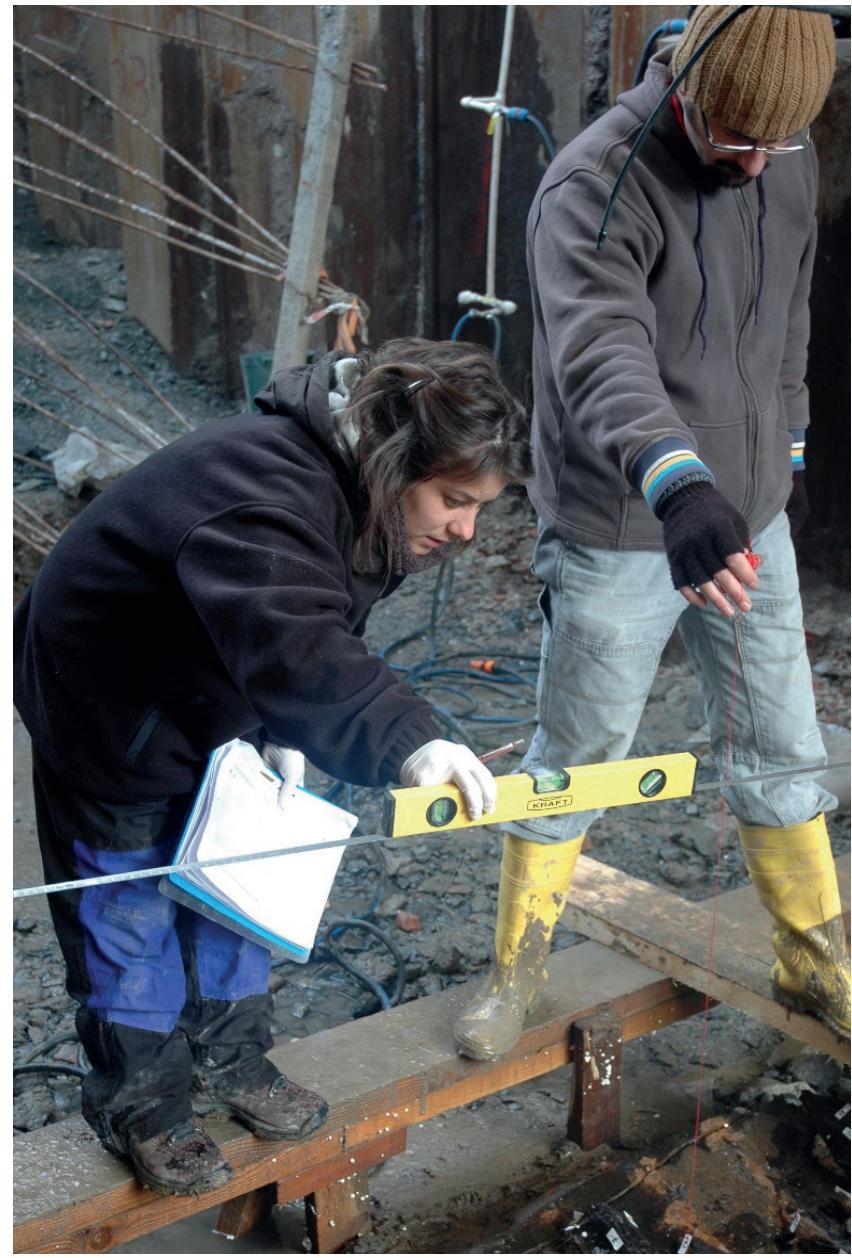

G. 3: Belgeleme çalışması (IÜ Yenikapı Batıkları Projesi Arşivi)

YK8'in kazı alanından kaldırılması için, ahşap elemanlarının sökülmesi yöntemi uygulanmıştır. İşlemlere başlanmadan önce kırık ahşap parçalar çelik tellerle birbirilerine tutturulmuş ve etiketlenmiştir. Sonrasında, gövde elemanları biçimsel özelliklerine ve korunmuşluk durumlarına göre belirlenen yöntemlerle demonte edilmiştir. Döşekler sağlam durumda oldukları için, kaplama bağlantıları kesildikten sonra, hazırlanan plakalara kolaylıkla alınmıştır. Dış kaplamalar için "L" profiller kullanılmıştır. Dış kaplamaların her biri, kendi biçimlerine göre hazırlanan bu profillerden oluşan düzenek sayesinde yerlerinden kaldırılmıştır. Alanda bulunan diğer batıklarda olduğu gibi, YK8 batığının omurgası da kendi ağırlığını taşıyamayacak durumda olduğundan, omurga biçiminde kesilmiş bir tahta platformdan yararlanılmıştır. Omurga, yan yüzeyine yaslanan bu platform ile birlikte yavaşça yatırılarak desteklenmiştir. Sökülerek birbirlerinden ayrılan ahşap elemanlar, boyutlarına göre inşa edilen ahşap 
kasalara yerleştirilerek, bekletilecekleri havuzlarda su hareketlerinden etkilenmemeleri için, strafordan yapılan küçük takozlarla sabitlenmiştir (G. 4). Daha sonra, kasalar içindeki ahşap parçalar İstanbul Üniversitesi Yenikapı Batıkları Araştırma Merkezi'ndeki tuzdan arındırma havuzlarına taşınarak pasif koruma altına alınmıştır. ${ }^{4}$

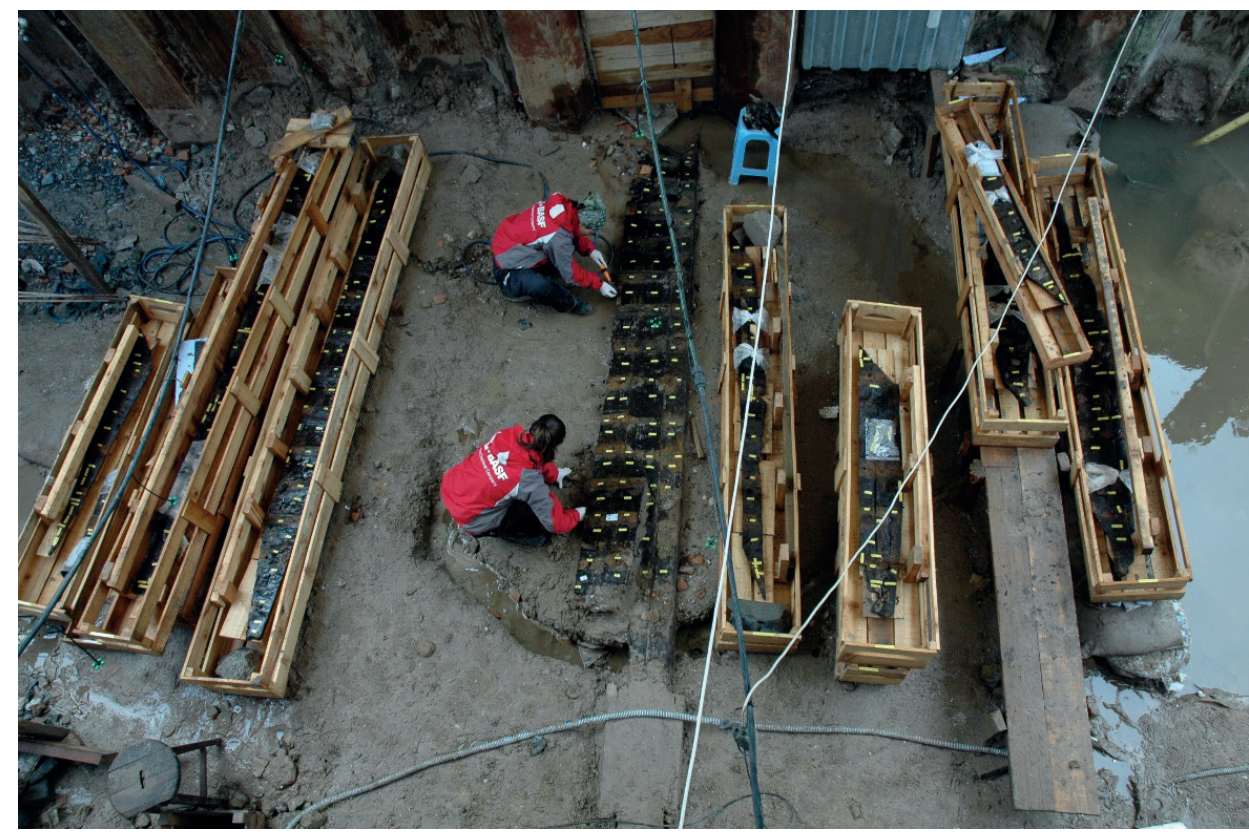

G. 4: Batık ahşaplarının sökülmesi (İ̈̈ Yenikapı Batıkları Projesi Arşivi)

\section{Konstrüksiyon Özellikleri}

Bir tarafına doğru çok hafif bir eğimle deniz tabanına oturmuş olan YK8'in, 2,9 m genişlik ve $5 \mathrm{~m}$ uzunluktaki in situ gövde kalıntısı bütün halde günümüze ulaşmıştır. Bu kalıntı bir omurga parçası, 19 adet kaplama tahtası ve 13 adet eğriden oluşmaktadır (G. 5). Karina dönüşünden sonraki kaplamaları, çapa tahtaları, postaları, yelken yatağı gibi üst gövde elemanlarının kayıp olmasına rağmen, mevcut gövdenin kalın eğrileri ve geniş formu, teknenin tok ve sağlam yapısı hakkında fikir vermektedir. ${ }^{5}$ Yelken yatağının konumu teknelerin baş-kıç yönlendirmesinde oldukça belirleyici bir faktördür. Mevcut eğriler üzerinde yelken yatağına dair herhangi bir iz veya oturtma yuvası bulunmaması, teknenin korunan kısmının gövdenin kıç tarafı olduğu yönünde değerlendirilmiştir.

4 Ufuk Kocabaş, Işı1 Özsait Kocabaş, Namık Kılıç, "The Yenikapı Shipwrecks: Dismantling Methodsand First Step to Conservation", $\mathbf{1 1}^{\text {th }}$ ICOM International Conference on Wet Organic Archaeological Materials (ICOM-WOAM), Eds. Kristiane Straetkvern, Emily Williams, İstanbul 2012, s. 303-312; Ufuk Kocabaş, Evren Türkmenoğlu, "Yenikapı Shipwrecks: Fieldwork, Conservation-Restoration Proceduresand Construction Features", Arqueologia Nàutica Mediterrània, Ed. Xavier Nieto, Girona 2009, s. 235-243.

5 Işı1 Özsait Kocabaş, Ufuk Kocabaş, "V. Technologicaland Constructional Features of Yenikapı Shipwrecks: A Preliminary Evaluation”, The 'OldShips' of the 'New Gate' 1, Yenikapı Shipwrecks, Vol. I, Ed. Ufuk 


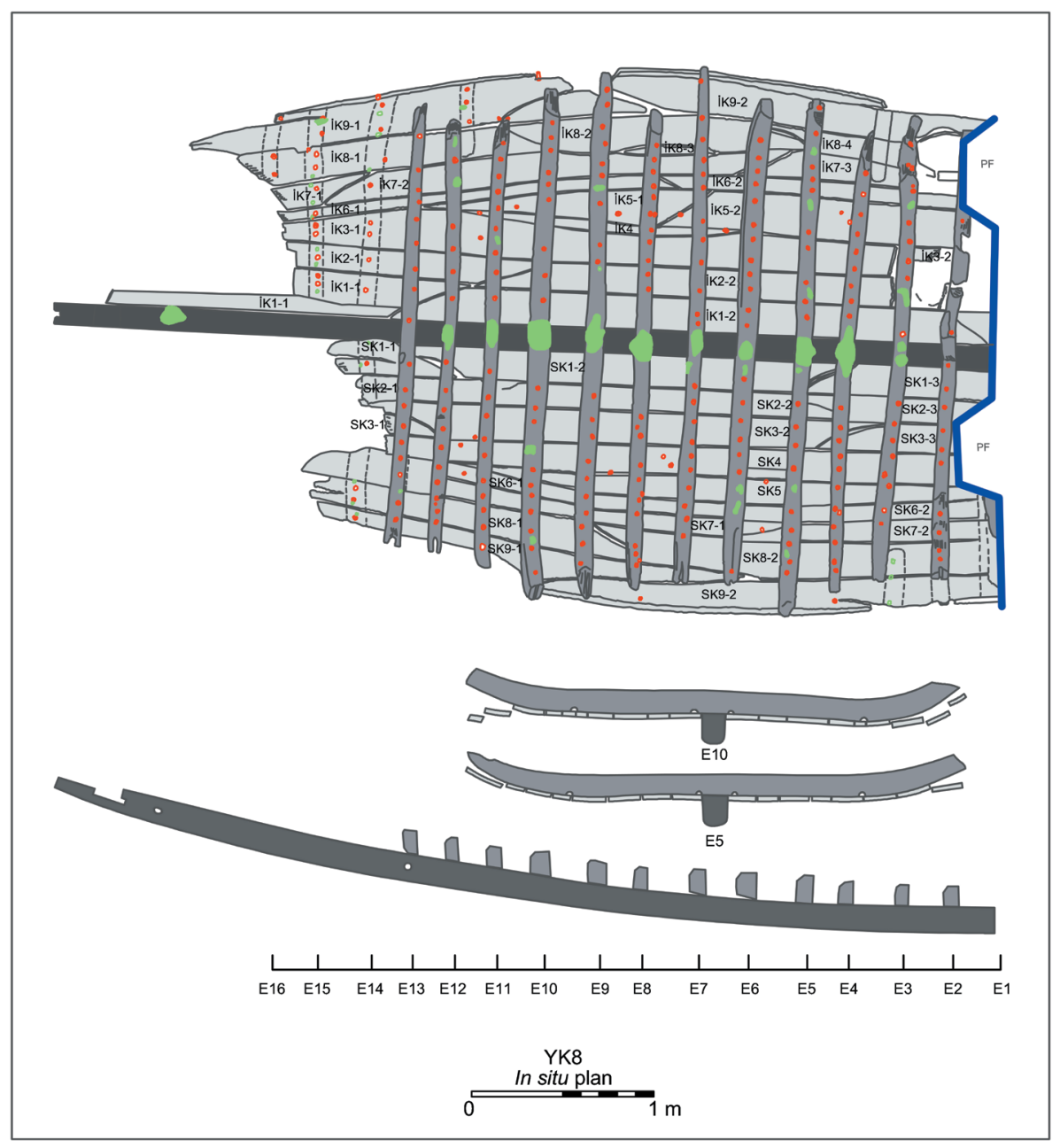

G. 5: YK8'in situ planı ve kesitleri (I. Özsait Kocabaş, dijital versiyon/DV Ç. Şanlıgençler)

\section{Gövde Ahşapları}

\section{Omurga}

$5 \mathrm{~m}$ uzunluğunda, ortalama $12 \mathrm{~cm}$ genişlik ve $12 \mathrm{~cm}$ kalınlıkta olan omurgası tek parçadır. Palplanşın kestiği ucu hasarlı diğer ucu ise geçme yeri ile birlikte sağlamdır. Üst yüzeyi düz olan omurganın iki yanı aşozsuzdur. Omurganın orta kısmında (ÇD1) ve parilesine yakın bir noktada (ÇD2) birer çekek deliği mevcuttur. Bu deliklerden 5 cm çapında olan ÇD1, içi macun ve kalafatla dolu olarak bulunmuştur. ÇD2'nin bodoslama tarafına doğru aşınması mevcuttur (G. 6). Bu deliklerin teknenin karaya çekilmesi sırasında kullanıldığı; diğer zamanlarda ise içlerinin doldurulduğu düşü- 
nülmektedir. Benzer çekek delikleri bazı Yenikapı batıklarında da belirlenmiştir. ${ }^{6} \mathrm{MS}$ 6. yüzyılın ilk yarısına tarihlenen Dor 2001/1 batığının omurgasında teknenin karaya çekilmesi için kullanılan benzer bir delik bildirilmiştir. ${ }^{7}$ Karadeniz tekne yapım geleneğinde, küçük teknelerin karaya çekilmesi için, omurganın uç kısmına ya da bodoslamaya delik açıldığı ve kullanılmadığında bu deliklerin tıkandığı bilinmektedir. ${ }^{8}$

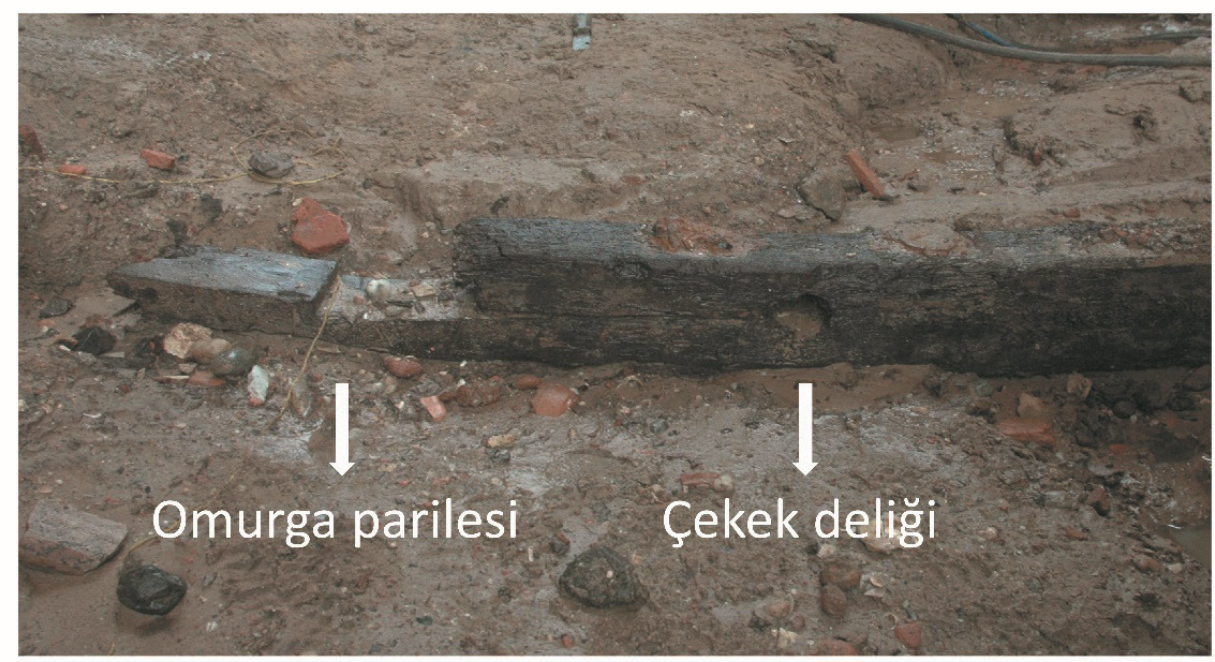

G. 6: Omurga parilesi ve çekek deliği (İ̈̈ Yenikapı Batıkları Projesi Arşivi)

\section{Kaplama Tahtalart}

Batığın karinasını oluşturan kaplama tahtaları, gövdenin bir tarafında 10 sıra diğer tarafında 9 sıra halinde korunmuştur. Kaplama tahtalarının genişlikleri $5 \mathrm{~cm}$ ile $22 \mathrm{~cm}$ arasında değişmektedir. İki ucu da korunmuş olan kaplamaların uzunlukları yaklaşık 3,5 m’ye ulaşmaktadır. Kaplama tahtaları gövde ortasında çok sayıda, farklı uzunlukta ve farklı tipte parileler ile birbirine eklenmiştir. Başlıca birleştirme diyagonal (G. 7a) ve S-biçimli parileler (G. 7b) ile yapılmıştır. Bir kaplama sırasında eğimli düz parile belirlenmiştir (G. 7c). Parileler, gövdenin iki tarafında simetrik bir düzende ve yönleri dönüşümlü olarak tasarlanmıştır. Ortalama kalınlı̆̆ı $25 \mathrm{~mm}$ olan kaplama tahtaları arasında sık aralılarla yerleştirilmiş kenar-kavelaları tespit edilmiştir (G. 8).

6 Ufuk Kocabaş, "The Yenikapı Byzantine-Era Shipwrecks, Istanbul, Turkey: A Preliminary Report and Inventory of the 27 Wrecks Studiedby İstanbul University", IJNA, S. 44.1, 2015, s. 74; Cemal Pulak, Rebecca Ingram, Michael Jones. "Eight Byzantine Shipwrecks from the Theodosian Harbour Excavations at Yenikap1 in Istanbul, Turkey: An Introduction”, IJNA, S. 44.1, 2015, s. 52.

7 Yaacov Kahanov, Hadas Mor, “The Dor 2001/1 Byzantine Shipwreck, Israel: Final Report”, IJNA, S. 43.1, 2014, s. 42.

8 Gemi inşa ustası Hüseyin Bakan ile birebir görüşme, Amasra, Ekim 2009. 

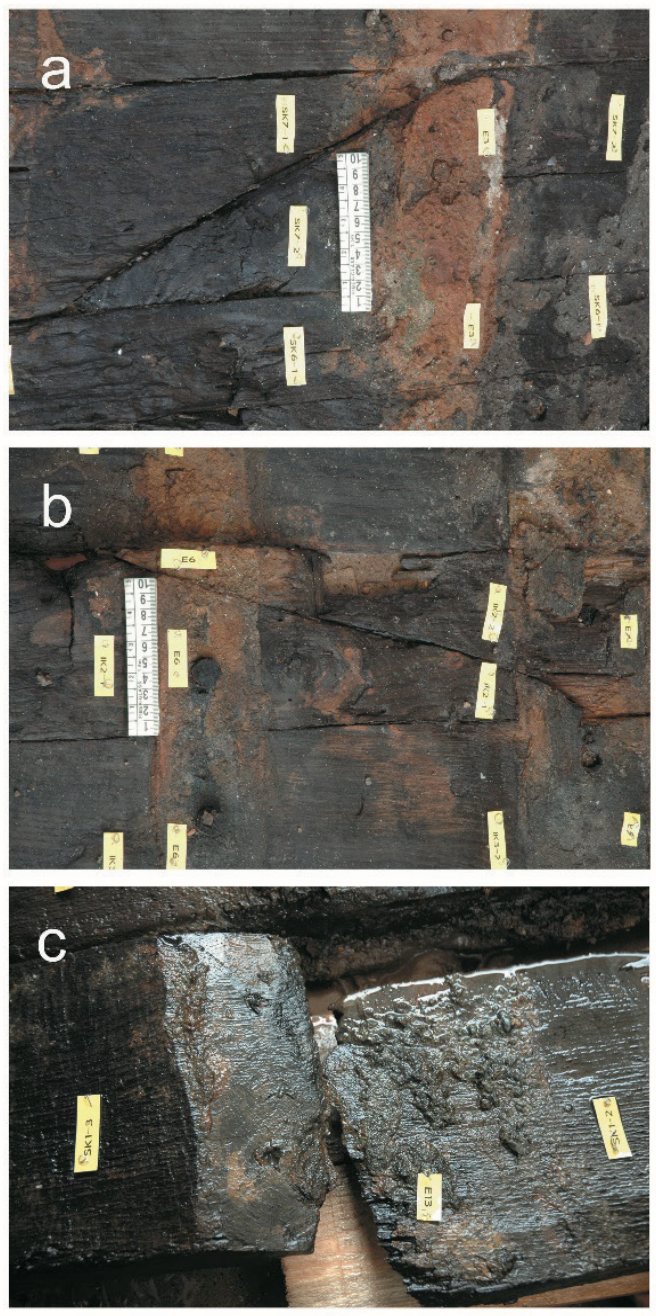

G. 7: Batığın parileleri (İ̈̈ Yenikapı Batıkları Projesi Arşivi) 


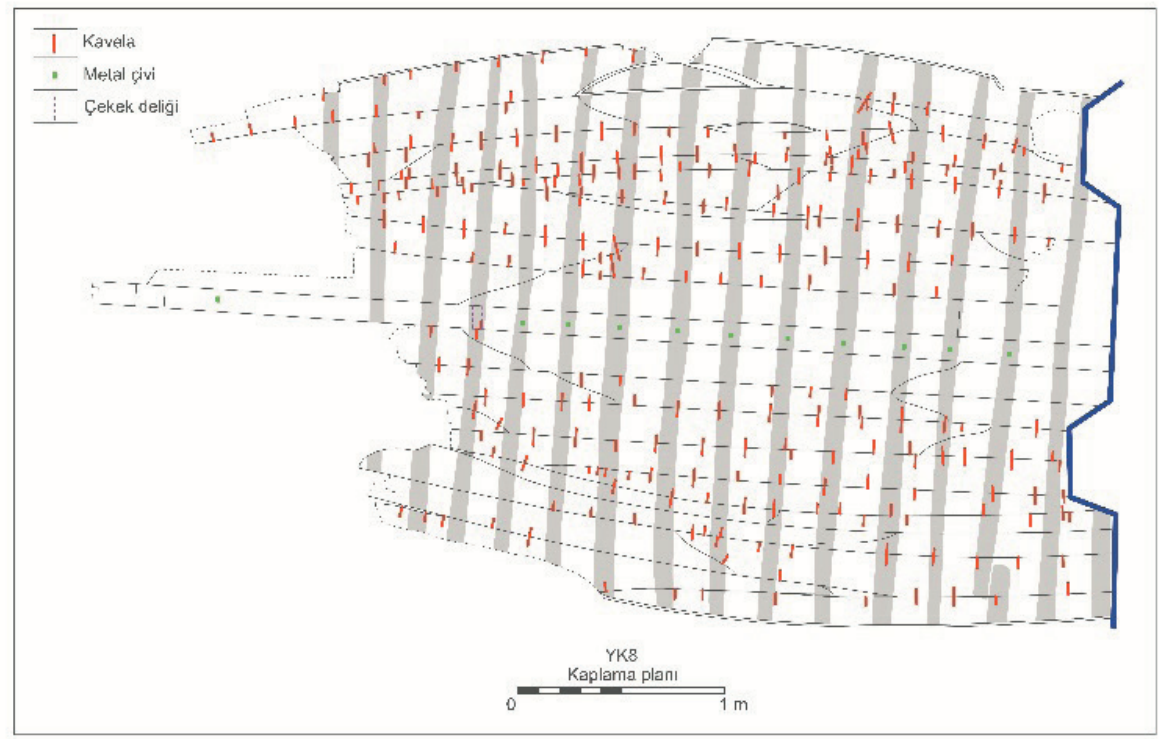

G. 8: Kaplama planında parileler ve kenar-kavelalarının dağılımı (I. Özsait Kocabaş, DV Ç. Şanlıgençler)

\section{Ĕgri Sistemi}

Batığın 13 döşeği günümüze ulaşmıştır (G. 9). Ayrıca omurga ve kaplamalar üzerindeki izlerden 5 adet döşeğin yeri belirlenmiştir. Mevcut döşekler oldukça sağlam ve düzgün yapıdadır. Ancak çoğunun ucu kırıktır. Teknenin postaları kayıptır. Kaplamalar üzerindeki izlere göre, E3, E4 ve E12 numaralı döşeklerin 8. ve 9. kaplama sıralarında birer yan postası olduğu belirlenmiştir. Oldukça düz dipli devam eden döşekler ortalama 8-11 cm genişlikte ve $12 \mathrm{~cm}$ kalınlığındadır. Dikdörtgen biçimli enine kesitlerinin bir tarafı tamamen düz, diğer tarafı ise üst köşesinde bir pah'a sahiptir. Pahlı kısımlar omurga boyunca aynı yönde devam etmektedir. Döşekler, omurganın iki tarafında birer ve karina dönüşlerinde birer tane, olmak üzere 4 adet yarım daire sintine deliğine sahiptir. YK7, YK14 ve YK20 batıklarının bazı eğrilerinde bu tip dairesel sintine delikleri belirlenmiştir. ${ }^{9}$ YK8' in eğri paterni tam döşeklerden oluşmuştur. Döşekler 22-30 cm aralıklarla omurgaya yerleştirilmiş ve demir çivilerle bağlanmıştır. Döşek ve kaplama tahtaları arasındaki bağlantılar ahşap çiviler ve demir çiviler ile yapılmıştır.

9 Michael Jones, "The Hull Construction of Yenikap1 14 (YK 14), a Middle Byzantine Shipwreck from Constantinople's Theodosian Harbour, İstanbul, Turkey", IJNA, S. 46.2, 2017, s. 269; Taner Güler, "Construction Technique of the Yenikap1 20 Shipwreck, Found in the Harbour of Theodosius (Istanbul, Turkey)", Shipand Maritime Landscapes, Proceedings of the Thirteenth International Symposium on Boatand Ship Archaeology, Amsterdam 2012, Eds. Jerzy Gawronski, Andrévan Holk, Joost Schokkenbroek, Eelde 2017, s. 280-282; Iş1 Özsait Kocabaş, Ufuk Kocabaş, a.g.e., s. 137. 


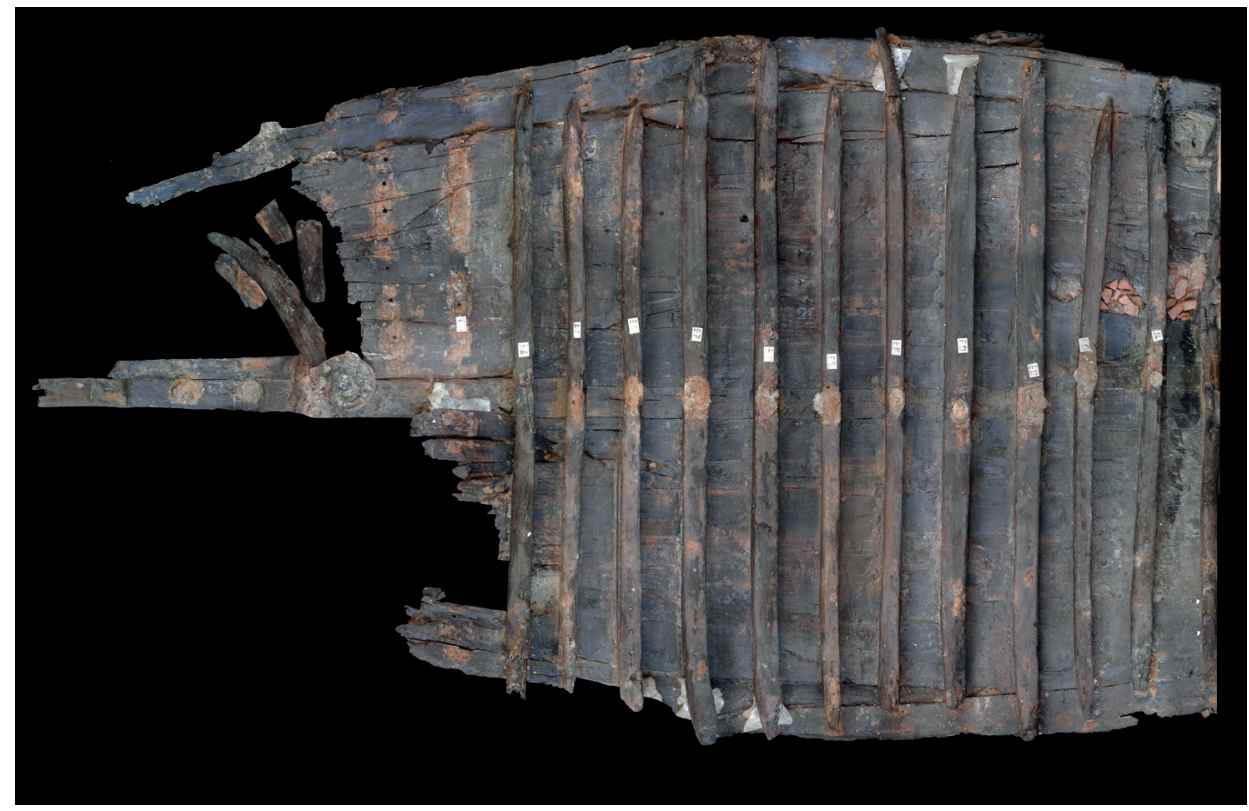

G. 9: YK8'in eğrili foto-mozaiği (İ̈̈ Yenikapı Batıkları Projesi Arşivi)

\section{Ahşap Analizleri}

Ahşap cins/türlerinin belirlenmesi için YK8 batığı ahşaplarından 54 örnek alınmıştır. Yapılan analizler sonucunda, tekne inşasında kestane, meşe, ceviz, kayın ve karaçam olmak üzere 5 farklı cinste ağaç kullanıldığı saptanmıştır (G. 10). Omurgada doğu kayını; dış kaplamalarda ağırlıklı olarak Anadolu kestanesi tercih edilmiştir. Birkaç kaplama akmeşe ve biri karaçam olarak tanımlanmıştır. Döşekler çoğunlukla akmeşeden şekillendirilmiştir. Birer döşek ceviz ve kırmızı meşe ağacındandır. ${ }^{10}$

10 Ünal Akkemik, Yenikapı Shipwrecks Volume II: Woods of Yenikapı Shipwrecks, Istanbul 2015, s. 3234; Ünal Akkemik, Ufuk Kocabas, "Woods of Byzantine Trade Ships of Yenikap1 (Istanbul) and Changes in Wood Use from $6^{\text {th }}$ to $11^{\text {th }}$ Century", Mediterranean Archaeology and Archaeometry, S. 14.2, 2014 , s. 319. 


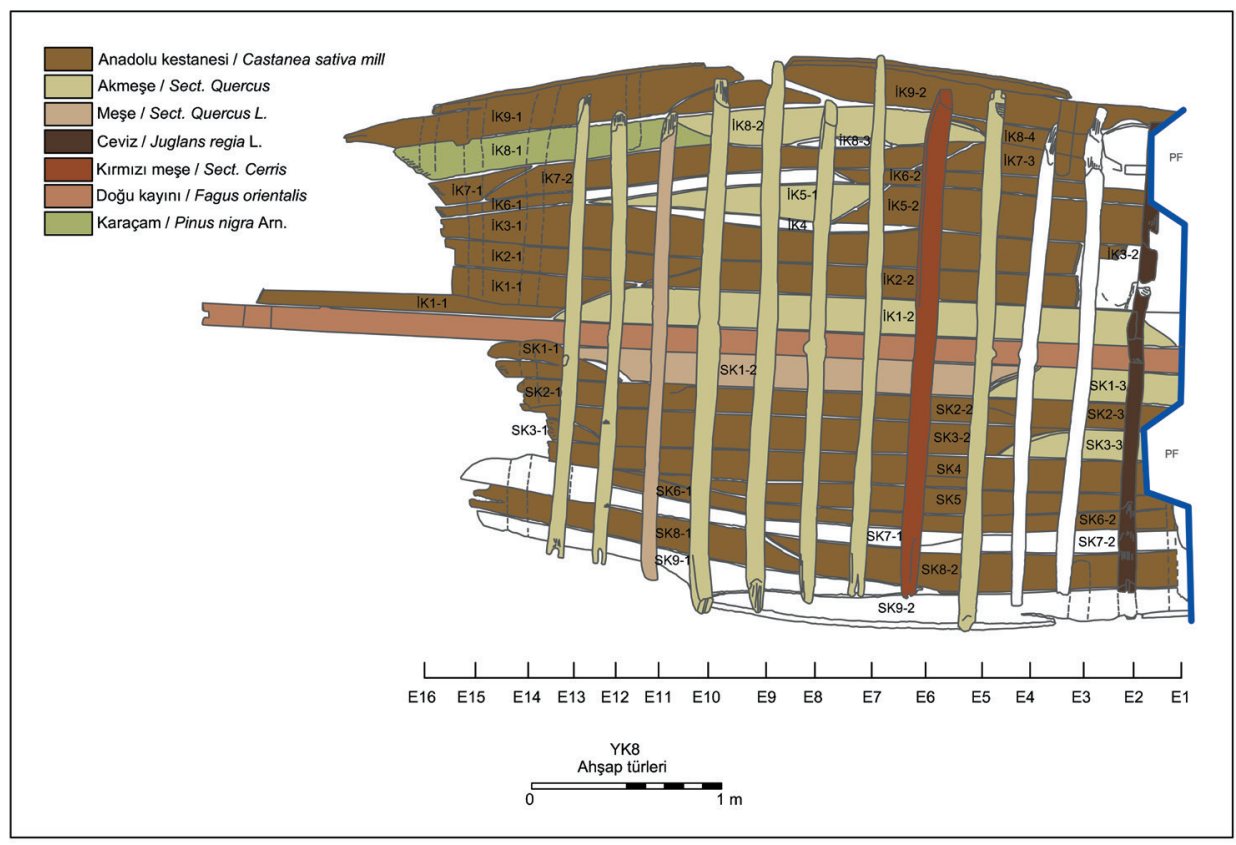

G. 10: YK8'de kullanılan ahşapların cins/türleri (Teşhis Ü. Akkemik, DV Ç. Şanlıgençler)

\section{Onarımlar}

YK8'in gövdesindeki onarımları gösteren en güzel kanıtları kaplamaların arasındaki kesilmiş kenar-kavelaları oluşturmuştur. Bir kaplama kenarı boyunca devam eden ve komşu kaplama kenarında olması gereken yerde karşılığ 1 bulunmayan kenar-kavelalarına göre, onarım tahtaları kolaylıkla belirlenmiştir. Örneğin teknenin burma tahtalarının iki tarafinda da kenar-kavelası yoktur. Bunun aksine, ikinci kaplama sıraları, burma tahtasına komşu olan yanları boyunca düzenli kenar-kavelalarına sahiptir. Burma tahtalarının teknedeki diğer kaplamaların aksine meşe ağacından yapılmış olması da bunların teknenin inşasından farklı bir zamanda, olasılıkla bir tamirat sırasında, eklenmiş olabileceği görüşünü desteklemektedir. Kaplamaların yanı sıra, bazı eğrilerin değiştirildiği tahmin edilmektedir. Gövde kaplamalarının iç yüzeylerinde, eğrilerin arasında ahşap çiviler tespit edilmiştir. Bunların etrafında kaplamaların armuzlarını geçer şekilde yaklaşık $8 \mathrm{~cm}$ kalınlığında bası izleri mevcuttur. Bu veri buralarda daha önceden var olan bazı eğrilerin söküldüğünün ve yenilerinin eklendiğinin bir göstergesi olarak yorumlanmıştır. Diğer döşeklerden farklı olarak, ceviz ve kırmızı meşeden yapılmış iki döşeğin varlığı bu kanıyı kuvvetlendirmektedir. 


\section{Değerlendirme ve Sonuç}

Theodosius Limanı'nda keşfedilen 37 adet batığın 6 adeti kadırgalar ve 31 adeti ticaret gemileri başlığı altında değerlendirilmiştir. ${ }^{11}$ Bunlar, gövde kaplamalarının bağlantılarından yola çıkarak zıvanalı, kenar-kavelalı ve kenar-birleştirmesiz tekne ve gemiler olarak üç ana grupta toplanmıştır. Gövdelerinin en geniş yerlerinin enine kesit geometrisine göre, düz dipli ve şarap kadehi biçimli olarak ikiye ayırabildiğimiz bu tekne ve gemiler, omurgalarının aşozlu ve aşozsuz oluşu ya da eğri paternlerine göre çeşitli alt gruplarda ele alınmaktadır. Yenikapı'nın kenar-kavelalı batıkları ortak konstrüksiyon özelliklerine sahiptir. Kaplama tahtaları kenar-kavelaları ile su hattına kadar birbirine bağlı olan bu teknelerin, büyük çoğunluğu düz diplidir. Dış kaplama tahtalarının boyuna birleşimlerinde ağırlıklı olarak diyagonal ve "S" parileler kullanılmıştır. Omurgalarına çekek delikleri yapılmıştır. YK8 kenar-kavelalı ve kestane ağacından kaplamaları, tam döşekli eğri paterni, dümdüz tabanlı gövdesi ve aşozsuz omurgası ile İstanbul Üniversitesi'nin çalıştığı batıklar arasında YK6, YK7, YK9 ile yakın konstrüksiyon özellikleri taşımaktadır. ${ }^{12}$ Bu batıklar, YK12 ve YK20 ile birlikte Karadeniz ve Marmara çevresine özgü yöresel tekne grubu olarak değerlendirilmiştir. ${ }^{13}$ Geniş yapılı gövdesi ve daha kalın eğrileri ile bu batıklardan boyut olarak ayrılsa da, YK8'in aynı grupta yer alması önerilmektedir. YK8, yükü bulunmamış olmasına karşın, gövde altında ve etrafında bulunan amforalar ve içinde bulunduğu liman konteksti, geniş ve sağlam gövde yapısı doğrultusunda ticaret teknesi olarak tanımlanmıştır. Yapılan ön rekonstrüksiyon çalışmalarına göre teknenin orijinal boyutları 12 m uzunluk ve 4 m genişlik olarak hesaplanmıştır. Bizans kaynaklarında dönemin ticaret tekneleri düz dipli, geniş döşekli, baş ve kıç bodoslamaları kavisli olarak tasvir edilmektedir. Bu tekneler Latin yelken donanımı ile hareket ettirilmekte ve bir çift omuzluk dümeni ile yönlendirilmektedir. ${ }^{14}$ Gövde tipi ile bu tanımını karş1layan YK8'in tek direkli, yelkenli ve omuzluk dümenleri ile yönlendiren bir Bizans teknesi olduğunu söylemek mümkün görünmektedir.

Akdeniz batıkları üzerindeki yapım teknolojisi çalışmaları, farklı uçlardaki iki inşa kavramının karşılaştııılması ile yola çıkar. Bunlar, inşaya omurga ve kaplamaların kurulumuyla başlandığı kabuk-temelli yöntem ve omurganın üzerine kaplamalardan önce tasarlanmış eğri sisteminin yerleştirildiği iskelet-temelli yöntemdir. Kaplama inşa felsefesinden, iskelet inşa felsefesine doğru gerçekleşen teknoloji kayışında kullanılan teknikler karma inşa olarak tanımlanmaktadır. Karma inşa teknikleri, MS 2. yüzyıl ortalarından itibaren başlayan ve 11. yüzyılda hala devam eden uzun bir zaman

11 Ufuk Kocabaş, a.g.m., s. 1-35; C. Pulak, R. Ingram, M. Jones, a.g.m., s. 39-73.

12 Iș1 Özsait Kocabaş, "The Yenikapı 12 Shipwreck, a 9th-Century Merchantman from the Theodosian Harbour in Istanbul, Turkey: Construction and Reconstruction", IJNA, S. 47.2, 2018, s. 380-382.

13 Işs1 Özsait, a.g.m., s. 371; Ü. Akkemik, a.g.e., s. 197.

14 John H. Pryor, Akdeniz'de Coğrafya, Teknoloji ve Savaş, Araplar, Bizanslılar, Batılılar ve Türkler, Çev. Füsun Tayanç ve Tunç Tayanc, İstanbul 2004, s. 48-49; Journeys on the Seas of Byzantium, Ed. Diana Zafiropoulou, Athens 1997, s. 37-38, 84. 
diliminde uygulanmıştır. ${ }^{15}$ Yenikapı'daki tekne ve gemiler, bu teknoloji değişiminin 5. ve 11. yüzyıllar arasındaki farklı aşamalarını gözler önüne sunmaktadır. YK8 batığının konstrüksiyonu, karma inşanın 10. yüzyılda uygulanma tarzını yansıtır. Kaplama tahtalarının birleştirilmesinde kullanılan sık aralıklı kenar-kavelaları, gövdenin iki yanındaki simetrik kurulum ve dönüşümlü parile yönleri YK8'in inşasında kaplamalardan oluşan kabuk yapıya verilen önemi vurgular. Bunun yanı sıra, benzer ve düzgün biçimlerdeki eğriler ve bunların düzenli aralıklarla yerleştirilerek omurgaya çivilenmiş olması iskeletin tekne tasarımındaki değerini gösterir. YK8 geçiş döneminin sonlarına gelindiği düşünülen bir tarihte, en azından inşa edildiği yörede, gövdeyi oluştururken kabuğa verilen önemin hala devam ettiği ve gövde dayanımında iki yöntemin birbirini tamamladığını gösteren güzel bir örnektir.

\section{Katkı Belirtme}

İstanbul Arkeoloji Müzeleri'ne; İÜ Yenikapı Batıkları Projesi Başkanı Prof. Dr. Ufuk Kocabaş'a; İÜ Yenikapı Batıkları Projesi Ekibine; batığın ahşap analizlerini gerçekleştiren Prof. Dr. Ünal Akkemik'e; YK8 batığının çizimlerini dijital versiyonda hazırlayan Çisil Şanlıgençler'e ve İstanbul Üniversitesi'nin ilgili birimlerine sonsuz teşekkürlerimi sunarım.

\section{Kaynakça/References}

AKKEMIK, Ünal, Yenikapı Shipwrecks Volume II: Woods of Yenikapı Shipwrecks/ Yenikapı Batıkları Cilt II: Yenikapı Batıklarının Ahşapları, Istanbul 2015.

AKKEMIK, Ünal; KOCABAŞ, Ufuk, "Woods of Byzantine Trade Ships of Yenikapı (Istanbul) and Changes in WoodUsefrom 6th to 11th Century", Mediterranean Archaeology and Archaeometry, S.14.2, 2014, s. 317-327.

BELTRAME, Carlo; BONDIOLI, Mauro, “A Hypothesis on the Development of Mediterranean Ship Construction from Antiquity to the Late Middle Ages", Connected by the Sea, Proceedings of the Tenth International Symposium on Boat and Ship Archaeology, Roskilde 2003, Eds. Lucy Blue, Fred Hocker, Anton Englert, Oxford 2006, s. 89-94.

GÜLER, Taner, "Construction Technique of the Yenikap1 20 Shipwreck, Found in the Harbour of Theodosius (Istanbul, Turkey)", Shipand Maritime Landscapes, Proceedings of the Thirteenth International Symposium on Boatand Ship Archaeology, Amsterdam 2012, Eds. Jerzy Gawronski, Andrévan Holk, Joost Schokkenbroek, Eelde 2017, s. 280-282.

JONES, Michael, “The Hull Construction of Yenikap1 14 (YK 14), a Middle Byzantine Shipwreck from Constantinople's Theodosian Harbour, Istanbul, Turkey”, IJNA, S. 46.2, 2017, s. 253-283.

15 Patrice Pomey, Yaacov Kahanov, Eric Rieth, "Transition from Shell to Skeleton in Ancient Mediterranean Ship-Construction: Analysis, Problems, and Future Research", IJNA, S. 41.2, 2012, s. 307; Carlo Beltrame, Mauro Bondioli, "A Hypothesis on the Development of Mediterranean Ship Construction from Antiquity to the Late Middle Ages", Connected by the Sea, Proceedings of the Tenth International Symposium on Boat and Ship Archaeology, Roskilde 2003, Eds. Lucy Blue, Fred Hocker, Anton Englert, Oxford 2006, s. 92-93. 
KAHANOV, Yaacov; MOR, Hadas, "The Dor 2001/1 Byzantine Shipwreck, Israel: Final Report", IJNA, S. 43.1, 2014, s. 41-65.

KIZILTAN, Zeynep, "Excavations at Yenikap1, Sirkeci and Üsküdar with in Marmaray and Metro Projects, Istanbul Archaeological Museums", Proceedings of the 1st Symposium on Marmaray-Metro Salvage Excavations 5th-6th May 2008, Ed. Ufuk Kocabaş, Istanbul 2010, s. 1-16.

KOCABAŞ, Ufuk, "The Yenikapı Byzantine-Era Shipwrecks, Istanbul, Turkey: A Preliminary Report and Inventory of the 27 Wrecks Studied by Istanbul University", IJNA, S. 44.1, 2015, s. $1-35$.

KOCABAŞ, Ufuk; ÖZSAİT KOCABAŞ, Işı1; KILIÇ, Namık, “The Yenikapı Shipwrecks: Dismantling Methods and First Step to Conservation", $\mathbf{1 1}^{\text {th }}$ ICOM International Conference on Wet Organic Archaeological Materials (ICOM-WOAM), Eds. Kristiane Straetkvern, Emily Williams, Istanbul 2012, s. 303-312.

KOCABAŞ, Ufuk; TÜRKMENOĞLU, Evren, "Yenikap1 Shipwrecks: Fieldwork, ConservationRestoration Procedures and Construction Features", Arqueologia Nàutica Mediterrània, Ed. Xavier Nieto, Girona 2009, s.235-243.

ÖZSAİT KOCABAŞ, Işı1, "III. Documentation: Reading the Timber", The 'Old Ships' of the 'New Gate' 1, Yenikapı Shipwrecks, Vol. I, Ed. Ufuk Kocabaş, Istanbul 2008, s. 27-72.

ÖZSAİT KOCABAŞ, Iş1, "The Yenikap1 12 Shipwreck, a 9th-Century Merchantman From the Theodosian Harbour in Istanbul, Turkey: Construction and Reconstruction”, IJNA, S. 47.2, 2018, s. 357-390.

ÖZSAİT KOCABAŞ Iş1; KOCABAŞ, Ufuk, "V. Technological and Constructional Features of Yenikapı Shipwrecks: A Preliminary Evaluation”, The 'Old Ships' of the 'New Gate' 1, Yenikapı Shipwrecks, Vol. I, Ed. Ufuk Kocabaş, Istanbul 2008, s. 97-186.

POMEY, Patrice; KAHANOV, Yaacov; RIETH, Eric, "Transitionfrom Shell to Skeleton in Ancient Mediterranean Ship-Construction: Analysis, Problems, and Future Research", IJNA, S. 41.2, 2012, s. 235-314.

PRYOR, John H., Akdeniz'de Coğrafya, Teknoloji ve Savaş, Araplar, Bizanslılar, Batılılar ve Türkler, Çev. Füsun Tayanç ve Tunç Tayanc, İstanbul 2004.

PULAK, Cemal; INGRAM, Rebecca; JONES, Michael, "Eight Byzantine Shipwrecks from the Theodosian Harbour Excavations at Yenikap1 in Istanbul, Turkey: an introduction", IJNA, S. $44.1,2015$, s. 39-73.

Journeys on the Seas of Byzantium, Ed. Diana Zafiropoulou, Athens 1997. 